\title{
Related Rule Study of Subcritical Crack Growth and Threshold Values in Transversely Isotropic Slates
}

\author{
Gang Ma, ${ }^{1}$ Jiangteng $\mathrm{Li} \stackrel{\mathbb{D},}{ }{ }^{1}$ and Huiwen Wang ${ }^{2}$ \\ ${ }^{1}$ School of Resources and Safety Engineering, Central South University, Changsha 410083, China \\ ${ }^{2}$ China Design Group Co., Ltd., Nanjing 210000, China \\ Correspondence should be addressed to Jiangteng Li; ljtcsu@csu.edu.cn
}

Received 9 June 2020; Revised 31 July 2020; Accepted 5 October 2020; Published 30 October 2020

Academic Editor: Yanlin Zhao

Copyright $@ 2020$ Gang Ma et al. This is an open access article distributed under the Creative Commons Attribution License, which permits unrestricted use, distribution, and reproduction in any medium, provided the original work is properly cited.

\begin{abstract}
Elastic parameters and the subcritical crack growth of different bedding angle slate specimens were studied using uniaxial compression testing and the double torsion constant displacement load relaxation method using SANS and MTS Insight machines. To study the relations of the mode-I stress intensity factor $K_{I}$ versus the subcritical crack growth velocity $V$, the fracture toughness $K_{I C}$, the stagnation speed, and the threshold values, the double torsion constant displacement load relaxation method was carried out. The related rules between the bedding angles $(\beta)$ and the uniaxial compressive strength, fracture toughness, and threshold values were investigated. Experimental results show that the uniaxial compression, the fracture toughness, and the threshold value curves move to the bottom then increase with the increase of the $\beta$ angle. In addition, its fracture toughness is minimal when the $\beta$ angle of the slates is $45^{\circ}$, and crack initiation and crack propagation are generated under load, which can lead to the failure of the slate. $\lg K_{I}-\lg V$ relations of transversely isotropic slates measured by this method are in accordance with linear rules, which is in good agreement with the Charles theory. The range of $K_{0} / K_{I C}$ for these different bedding angle slates is from 0.511 to 0.789 . The test results would provide the basis for studying seepage and timedependency of rock engineering stability.
\end{abstract}

\section{Introduction}

Rocks are mineral aggregates after a long geological process; rocks of layered structure can be simplified into a transversely isotropic body, whose physical and mechanical properties in parallel to the bedding plane are different from those in perpendicular to the bedding plane. The stability analysis of the layered rock is complicated by the isotropic characteristics of the bedding surface and the coupling effect of the seepage field and stress field [1]. Thus, to reveal the transversely isotropic permeability mechanism, it is necessary to investigate the transversely isotropic fracture characteristics.

At present, the researches on anisotropic rock properties are mainly concentrated on the following areas: (1) the measurement method study of elastic deformation parameters [2], (2) the anisotropy strength and yield criterion study [3, 4], (3) anisotropic rock constitutive model study $[5,6]$, and (4) anisotropic rock deformation characteristics and mechanical property study $[7,8]$. Transverse isotropy is a special case of anisotropy; these studies have a great significance on helping us have a better understanding of the permeability and mechanical properties of transversely isotropic rocks. The instability instances in situ and rock laboratory examinations show that the rock failure is due to crack growth and propagation in rock mass [9], and the crack is the main seepage channel of the rock mass, which controls the seepage characteristics of the rock mass. According to the fracture mechanics and stress corrosion theory $[10,11]$, when a crack tip stress intensity factor $K_{I}$ exceeds its fracture toughness $K_{I C}$, the crack will quickly expand; when the stress intensity factor is less than its fracture toughness, the crack growth will process at the speed of stress corrosion subcritical crack growth. The study shows that the crack in certain circumstances propagates until the material fractures with a collective effect of tensile stress and corrosion medium, which is called stress corrosion [12]. Usually, the mode-I stress intensity factor $K_{I}$ at the crack tip is regarded as a parameter to control the crack growth. The stress corrosion lower limit is $K_{0}$; when the stress intensity factor is less than 
$K_{0}$, the crack will not extension; when the stress intensity factor is between $K_{I C}$ and $K_{I}$, the crack grows at a certain velocity; the reasons can be listed as follows: (1) the stresses at the crack tip increases in the process of forming a microcrack and interspace and (2) the chemical bond fracture stresses decrease by the effects of the environmental medium, so the crack grows at a stable and static state in the process, which is called subcritical crack growth. The crack growth in the rock mass happens after the subcritical cracks propagate to a certain extent. Therefore, studies of the subcritical crack growth laws and fracture properties are important to rock engineering long-term stability. The elastic parameters and the principle of subcritical crack growth can be obtained in the paper. The related laws between the bedding angles $(\beta)$ and compressive strength, fracture toughness, and threshold values had been analyzed. The relations of the mode-I stress intensity factor $K_{I}$ versus the subcritical crack growth velocity $V$ and the fracture toughness $K_{I C}$ will be able to predict when the crack will be extended to the critical crack length under certain stress conditions, the result of which can cause structural damage, which gives the permeability and mechanics study a new approach.

\section{Transverse Isotropy of Different Bedding Angle Slates}

2.1. Constitutive Relations of Transversely Isotropic Elastic Body. Transversely isotropic elastic body is made of an elastic symmetry plane, whose physical and mechanical properties in parallel to the elastic symmetry plane are different from those in perpendicular to the elastic symmetry plane. For the layered rock, engineering generally regards the bedding plane as an elastic symmetry plane; it is believed that it has the same physical and mechanical properties in parallel to the bedding plane which are different from those that are vertical to the elastic symmetry plane. As shown in Figure 1, the $X O Y$ plane is assumed as the elastic symmetry plane; the transversely isotropic elastic parameters should satisfy the following conditions [13]:

$$
\left.\begin{array}{l}
E_{x}=E_{y}=E, E_{z}=E^{\prime}, \\
\mu_{x y}=\mu_{y x}=\mu, \mu_{z x}=\mu_{z y}=\mu^{\prime}, \\
G_{x y}=\frac{E}{2(1+\mu)}, G_{y z}=G_{x z}=G_{2} .
\end{array}\right\}
$$

The transversely isotropic elastic body constitutive relation can be simplified as follows [14]:

$$
\left\{\begin{array}{c}
\varepsilon_{x} \\
\varepsilon_{y} \\
\varepsilon_{z} \\
\gamma_{x y} \\
\gamma_{y z} \\
\gamma_{x z}
\end{array}\right\}=[A]\left\{\begin{array}{c}
\sigma_{x} \\
\sigma_{y} \\
\sigma_{z} \\
\tau_{x y} \\
\tau_{y z} \\
\tau_{x z}
\end{array}\right\}=\left\{\begin{array}{cccccc}
a_{11} & a_{12} & a_{13} & 0 & 0 & 0 \\
& a_{11} & a_{23} & 0 & 0 & 0 \\
& & a_{33} & 0 & 0 & 0 \\
& & & a_{44} & 0 & 0 \\
& & & & a_{55} & 0 \\
& & & & & \\
& & & & & a_{55}
\end{array}\right\}\left\{\begin{array}{c}
\sigma_{x} \\
\sigma_{y} \\
\sigma_{z} \\
\tau_{x y} \\
\tau_{y z} \\
\tau_{x z}
\end{array}\right\},
$$

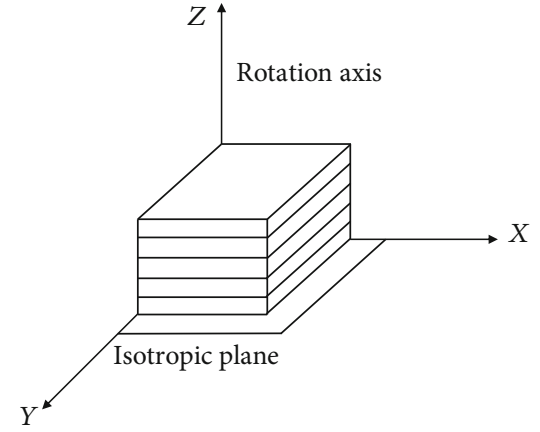

Figure 1: Transversely isotropic slate schematic view $\left(\beta=0^{\circ}\right)$.

where $[A]$ is the compliance matrix, which can be can be calculated by

$$
\left.\begin{array}{l}
a_{11}=\frac{1}{E}, a_{12}=-\frac{v}{E}, a_{13}=-\frac{v^{\prime}}{E}, \\
a_{33}=\frac{1}{E^{\prime}}, a_{44}=\frac{2(1+v)}{E}, a_{55}=\frac{1}{G^{\prime}},
\end{array}\right\}
$$

where $E$ and $v$ are Young's modulus of rock and Poisson's ratio in the direction parallel to the transversely isotropic plane, respectively; $E^{\prime}$ and $v^{\prime}$ is Young's modulus of rock and Poisson's ratio in the direction perpendicular to the transversely isotropic plane, respectively; and $G^{\prime}$ is the shear modulus for the plane normal to the transversely isotropic plane.

Because the stiffness matrix and the compliance matrix are inverse matrix, so the stiffness matrix $[C]$ can be calculated as follows:

$$
\begin{aligned}
& c_{11}=\lambda n\left(1-n v^{\prime 2}\right), c_{12}=\lambda n\left(v+n v^{\prime 2}\right), c_{13}=\lambda n v^{\prime}(1+v), \\
& c_{33}=\lambda\left(1-v^{2}\right), c_{44}=G^{\prime}, c_{66}=\frac{E}{[2(1+v)]},
\end{aligned}
$$

where $n=E / E^{\prime}$ and $\lambda=E^{\prime} /(1+v)\left(1-v-2 n v^{\prime 2}\right)$.

When an orthotropic body degenerates into a transversely isotropic elastic body, the nine independent elastic parameters are reduced to the five independent elastic parameters, respectively; $E, E^{\prime}, G^{\prime}, v, v^{\prime}$, and $G$ are not independent elastic parameters, because of $G=E / 2(1+v)$.

2.2. Coordinate Conversion of the Anisotropic Elastic Constants. Due to the different mechanical properties of the rock in all directions in anisotropic media, the coordinate system often needs to be converted to solve the elastic parameters, and coordinate transformation of anisotropic elastic parameters generally follows the tensor rule.

The global coordinate system $(X, Y, Z)$ and the local coordinate system $\left(X^{\prime}, Y^{\prime}, Z^{\prime}\right)$ of a transversely isotropic body are shown in Figure 2; the local coordinate system 


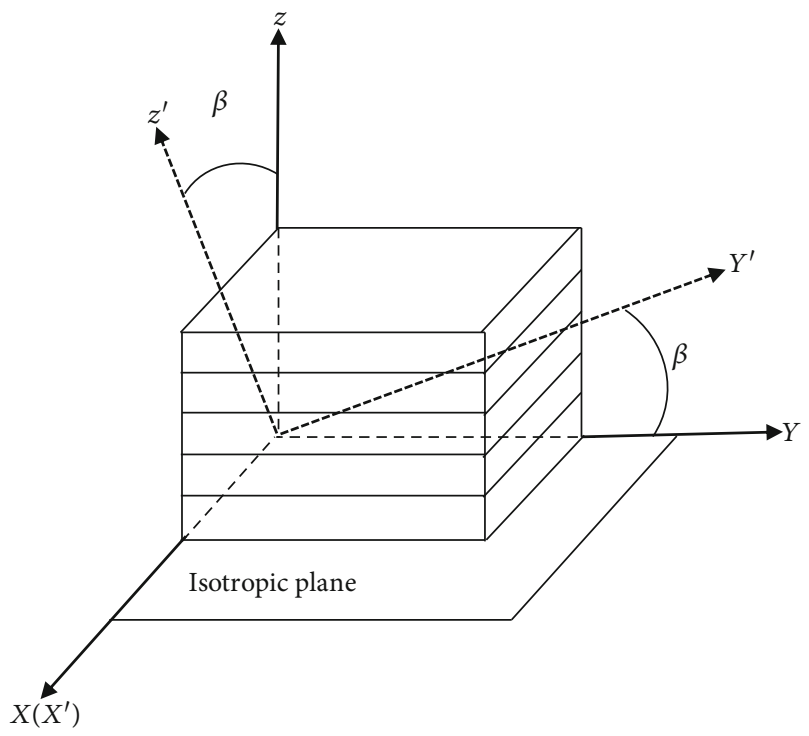

FIgURE 2: Transverse isotropic material schematic view.

around the $z$-axis rotates the $\beta$ angle to get the global coordinate system. Stiffness matrix $[C]$ in the local coordinate system can be converted to the stiffness matrix $[C]^{\prime}$ in the global coordinate system. It can be expressed as [13]

$$
[C]^{\prime}=[L]^{T}[C][L]
$$

where $[L]$ is the transformation matrix, which can be expressed as follows:

$$
[L]=\left[\begin{array}{ccc}
\cos ^{2} \beta & \sin ^{2} \beta & \sin \beta \cos \beta \\
\sin ^{2} \beta & \cos ^{2} \beta & -\sin ^{2} \beta \cos \beta \\
-2 \sin \beta \cos \beta & 2 \sin \beta \cos \beta & \cos ^{2} \beta-\sin ^{2} \beta
\end{array}\right] .
$$

Transversely isotropic elastic parameters in the local coordinate system can be transferred into the elastic parameters in the global coordinate system, which are shown as follows:

$$
\left\{\begin{array}{c}
\varepsilon_{x} \\
\varepsilon_{y} \\
\varepsilon_{z} \\
\gamma_{x y} \\
\gamma_{y z} \\
\gamma_{x z}
\end{array}\right\}=[A]\left\{\begin{array}{c}
\sigma_{x} \\
\sigma_{y} \\
\sigma_{z} \\
\tau_{x y} \\
\tau_{y z} \\
\tau_{x z}
\end{array}\right\}=\left\{\begin{array}{cccccc}
a_{11} & a_{12} & a_{13} & 0 & 0 & a_{16} \\
a_{12} & a_{22} & a_{23} & 0 & 0 & a_{26} \\
a_{13} & a_{23} & a_{33} & 0 & 0 & a_{36} \\
& & & a_{44} & a_{45} & 0 \\
& & & a_{45} & a_{55} & 0 \\
a_{16} & a_{26} & a_{36} & & & a_{66}
\end{array}\right\}\left\{\begin{array}{c}
\sigma_{x} \\
\sigma_{y} \\
\sigma_{z} \\
\tau_{x y} \\
\tau_{y z} \\
\tau_{x z}
\end{array}\right\},
$$

where $a_{11}, \cdots, a_{66}$ can be calculated by the following equations:

$$
\begin{aligned}
& a_{11}=\frac{1}{E} \cos ^{4} \beta+\frac{1}{E^{\prime}} \sin ^{4} \beta+\left(\frac{1}{G^{\prime}}-\frac{2 v^{\prime}}{E}\right) \sin ^{2} \beta \cos ^{2} \beta, \\
& a_{22}=\frac{1}{E} \sin ^{4} \beta+\frac{1}{E^{\prime}} \cos ^{4} \beta+\left(\frac{1}{G^{\prime}}-\frac{2 v^{\prime}}{E}\right) \sin ^{2} \beta \cos ^{2} \beta, \\
& a_{12}=\left(\frac{1}{E}+\frac{1}{E^{\prime}}+\frac{2 v^{\prime}}{E}-\frac{1}{G^{\prime}}\right) \sin ^{2} \beta \cos ^{2} \beta-\frac{v^{\prime}}{E}, \\
& a_{13}=-\frac{v^{\prime}}{E^{\prime}} \sin ^{2} \beta-\frac{v}{E} \cos ^{2} \beta \text {, } \\
& a_{23}=-\frac{v^{\prime}}{E^{\prime}} \cos ^{2} \beta-\frac{v}{E} \sin ^{2} \beta \text {, } \\
& a_{33}=\frac{1}{E} \text {, } \\
& a_{44}=\frac{\sin ^{2} \beta}{G}+\frac{\cos ^{2} \beta}{G^{\prime}}, \\
& a_{45}=\left[\frac{1}{G^{\prime}}-\frac{1}{G}\right] \sin \beta \cos \beta, \\
& a_{55}=\frac{\cos ^{2} \beta}{G}+\frac{\sin ^{2} \beta}{G^{\prime}}, \\
& a_{36}=2\left[\frac{v}{E}-\frac{v^{\prime}}{E^{\prime}}\right] \sin \beta \cos \beta, \\
& a_{16}=\left[2\left(\frac{\sin ^{2} \beta}{E^{\prime}}-\frac{\cos ^{2} \beta}{E}\right)+\left(\frac{1}{G^{\prime}}-\frac{2 v^{\prime}}{E}\right)\left(\cos ^{2} \beta-\sin ^{2} \beta\right)\right] \sin \beta \cos \beta, \\
& a_{26}=\left[2\left(\frac{\cos ^{2} \beta}{E^{\prime}}-\frac{\sin ^{2} \beta}{E}\right)+\left(\frac{1}{G^{\prime}}-\frac{2 v^{\prime}}{E}\right)\left(\cos ^{2} \beta-\sin ^{2} \beta\right)\right] \sin \beta \cos \beta, \\
& a_{66}=4\left(\frac{1}{E}+\frac{1}{E^{\prime}}+\frac{2 v^{\prime}}{E}-\frac{1}{G^{\prime}}\right) \sin ^{2} \beta \cos ^{2} \beta+\frac{1}{G^{\prime}} .
\end{aligned}
$$

2.3. Thermodynamic Constraint of Transversely Isotropic Constant. To make the rock strain energy positive in this experiment, the 5 elastic parameters of the transversely isotropic rock should meet the related inequality of hot mechanical constraints, which are expressed as follows [15]:

$$
\left.\begin{array}{l}
E, E^{\prime}, G^{\prime}>0, \\
-1 \leq v \leq 1, \\
-\sqrt{\frac{E^{\prime}}{E} \frac{1-v}{2}} \leq v^{\prime} \leq \sqrt{\frac{E^{\prime}}{E} \frac{1-v}{2}} .
\end{array}\right\}
$$

\section{Elastic Parameters of Transversely Isotropic Slate Specimen}

Elastic modulus, Poisson's ratio, and uniaxial compressive strength values of the cylinder slates whose diameter is $50 \mathrm{~mm}$ and height is $100 \mathrm{~mm}$ with different bedding angles $\left(0^{\circ}, 30^{\circ}, 45^{\circ}, 70^{\circ}, 80^{\circ}\right.$, and $\left.90^{\circ}\right)$ can be obtained by uniaxial compression test using the SANS machine, which are listed in Table 1.

According to the translation of rock mechanics by Milou and the relation between the constant in compliance matrix 
TABle 1: Elastic modulus, Poisson's ratio, and uniaxial compressive strength.

\begin{tabular}{|c|c|c|c|c|c|c|c|}
\hline \multirow[t]{2}{*}{$\begin{array}{l}\beta \\
\left({ }^{\circ}\right)\end{array}$} & \multirow[t]{2}{*}{ Specimen } & \multirow[t]{2}{*}{$\begin{array}{l}\text { Compressive strength } \\
(\mathrm{MPa})\end{array}$} & \multirow[t]{2}{*}{$\begin{array}{c}\text { The average of compressive } \\
\text { strength }(\mathrm{MPa})\end{array}$} & \multirow[t]{2}{*}{$\begin{array}{l}\text { Elastic modulus } \\
(\mathrm{MPa})\end{array}$} & \multirow[t]{2}{*}{$\begin{array}{l}\text { The average of elastic } \\
\text { modulus }(\mathrm{MPa})\end{array}$} & \multicolumn{2}{|c|}{$\begin{array}{l}\text { The } \\
\text { average of } \\
\text { Poisson's } \\
\text { ratio }\end{array}$} \\
\hline & & & & & & $\mu_{x z}$ & $\mu_{y z}$ \\
\hline \multirow{3}{*}{$0^{\circ}$} & $0-1$ & 70.08 & & 36.67 & & & \\
\hline & $0-2$ & 63.86 & 74.79 & 41.02 & 38.38 & 0.19 & 0.19 \\
\hline & $0-3$ & 90.43 & & 37.45 & & & \\
\hline \multirow{3}{*}{$30^{\circ}$} & $1-1$ & 35.56 & & 25.00 & & & \\
\hline & $1-2$ & 30.45 & 32.21 & 23.45 & 23.00 & 0.20 & 0.21 \\
\hline & $1-3$ & 30.65 & & 20.55 & & & \\
\hline \multirow{3}{*}{$45^{\circ}$} & $2-1$ & 32.45 & & 25.56 & & & \\
\hline & $2-2$ & 20.56 & 24.96 & 19.00 & 21.77 & 0.23 & 0.20 \\
\hline & $2-3$ & 21.87 & & 20.75 & & & \\
\hline \multirow{3}{*}{$70^{\circ}$} & $3-1$ & 30.20 & & 20.38 & & & \\
\hline & $3-2$ & 28.37 & 27.00 & 24.38 & 23.98 & 0.22 & 0.24 \\
\hline & $3-3$ & 22.43 & & 27.18 & & & \\
\hline \multirow{3}{*}{$80^{\circ}$} & $4-1$ & 56.36 & & 30.55 & & & \\
\hline & $4-2$ & 67.85 & 63.39 & 32.89 & 32.96 & 0.30 & 0.18 \\
\hline & $4-3$ & 65.96 & & 35.44 & & & \\
\hline \multirow{3}{*}{$90^{\circ}$} & $5-1$ & 71.16 & & 42.22 & & & \\
\hline & $5-2$ & 69.39 & 70.50 & 42.74 & 41.85 & 0.25 & 0.23 \\
\hline & $5-3$ & 70.95 & & 40.59 & & & \\
\hline
\end{tabular}

and elastic constants of rock, the following relationship can be obtained [16]:

$$
\begin{aligned}
& \frac{1}{E_{z}{ }^{\prime}}=\frac{\sin ^{4} \beta}{E_{1}}+\frac{\cos ^{4} \beta}{E_{2}}+\left(\frac{1}{G_{2}}-\frac{2 v_{1}}{E_{2}}\right) \sin ^{2} \beta \cos ^{2} \beta, \\
& v_{x z}{ }^{\prime}=-\frac{\varepsilon_{x}}{\varepsilon_{z}}=E_{1}\left(\frac{\nu_{1}}{E_{1}} \sin ^{2} \beta+\frac{v_{2}}{E_{2}} \cos ^{2} \beta\right), \\
& v_{y z}{ }^{\prime}=-\frac{\varepsilon_{y}}{\varepsilon_{z}}=\frac{v_{2} E_{1}}{E_{2}}-\left(1+\frac{E_{1}}{E_{2}}+2 v_{2} \frac{E_{1}}{E_{2}}-\frac{E_{1}}{G_{2}}\right) \sin ^{2} \beta \cos ^{2} \beta, \\
& \frac{1}{G_{x y}{ }^{\prime}}=\frac{\sin ^{2} \beta}{G_{2}}+2\left(1+v_{1}\right) \frac{\cos ^{2} \beta}{E_{1}}, \\
& \frac{1}{G_{x z}{ }^{\prime}}=\frac{\cos ^{2} \beta}{G_{2}}+2\left(1+v_{1}\right) \frac{\sin ^{2} \beta}{E_{1}}, \\
& \frac{1}{G_{y z}{ }^{\prime}}=\frac{1}{E_{1}}\left[4\left(1+\frac{E_{1}}{E_{2}}+2 v_{2} \frac{E_{1}}{E_{2}}-\frac{E_{1}}{G_{2}}\right) \sin ^{2} \beta \cos ^{2} \beta+\frac{E_{1}}{G_{2}}\right],
\end{aligned}
$$

where $E_{1}$ and $v_{1}$ are the elastic modulus and Poisson's ratio of the slate with a bedding angle of $90^{\circ}$, respectively; $E_{2}$ and $v_{2}$ are the elastic modulus and Poisson's ratio of the slate with a bedding angle of $0^{\circ}$, respectively; and $E_{\beta}$ is the elastic modulus of the slate with $\beta$ bedding angle.

For the slates with a certain angle between the transversely isotropic plane and horizontal plane, $G_{x y}, G_{x z}$, and $G_{y z}$ of the slate specimen in three orthogonal directions can be obtained by Equation (10), which are listed
TABLE 2: Shear modulus of slate rock specimen at different angles.

\begin{tabular}{lcccccc}
\hline$\beta$ & $0^{\circ}$ & $30^{\circ}$ & $45^{\circ}$ & $70^{\circ}$ & $80^{\circ}$ & $90^{\circ}$ \\
\hline$G_{x y}$ & 16.89 & 13.20 & 8.38 & 6.05 & 5.69 & 5.57 \\
$G_{x z}$ & 5.57 & 8.38 & 8.70 & 13.65 & 15.96 & 16.89 \\
$G_{y z}$ & 5.57 & 13.05 & 16.68 & 7.69 & 5.68 & 16.89 \\
\hline
\end{tabular}

in Table 2. Based on the transversely isotropic and loading direction of the slate, we select $G_{x z}$ as the shear modulus of the slate specimen in the calculation of its fracture toughness.

\section{The Relations between Bedding Angles of Slate Specimen and Uniaxial Compressive Strength and Elastic Modulus}

For the layered rock with a single layer, its bedding angles have a great influence on its destructive strength. For the slates in this experiment, it can be considered as the transversely isotropic constitutive model which has only one set of parallel beddings with different angles loaded. We can obtain the related law between the bedding angles of the slate specimen and the uniaxial compressive strength and elastic modulus from Table 1, which can be expressed as Figure 3, from which we can know that the bedding angles have a great effect on the uniaxial compressive strength and elastic modulus of the slates. What is more, the uniaxial compression and elastic modulus decreases then 


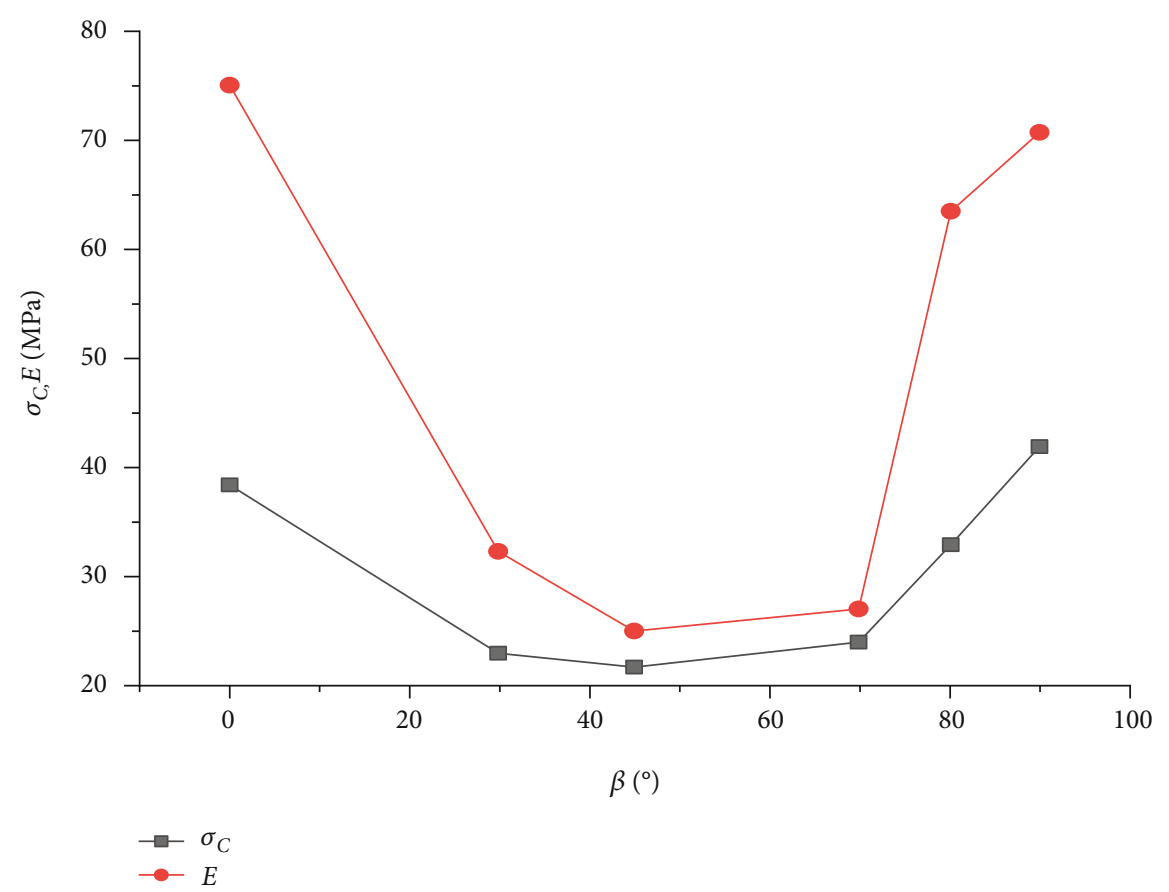

Figure 3: The relations between $\beta$ angles and compressive strength and elastic modulus.

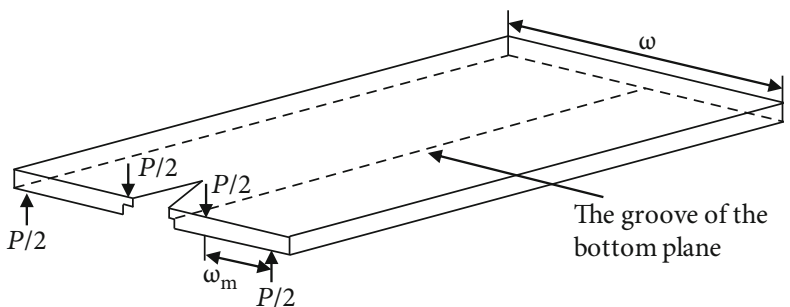

(a)

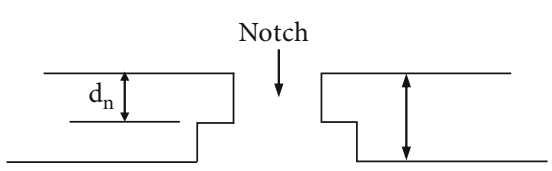

(b)

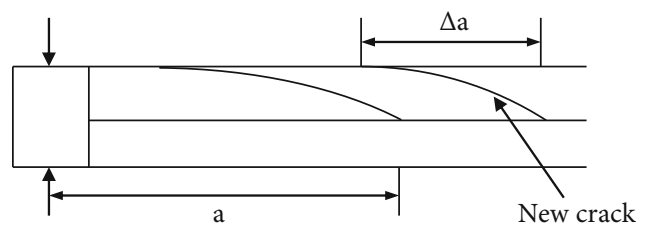

(c)

FIGURE 4: Schematic diagram of double torsion specimen: (a) specimen plane; (b) "V"-style cut schematic; (c) crack growth.

increases with the increase of $\beta$ angle and the relation curves show a " $U$ " type. The results show that when the $\beta$ angle of the slate is $45^{\circ}$, its uniaxial compression and elastic modulus are minimal. Therefore, it is most likely to be damaged when the bedding angle of slates is $45^{\circ}$.

\section{Double Torsion Method}

5.1. Principle of Double Torsion Testing. The double torsion specimen was first adopted by Williams and Evans [17] to decide the fracture properties of glass and ceramics, which is shown in Figure 4. Since 1977, Ciccotti et al. [18], Saadaoui et al. [19], and Nara and Kaneko [20] applied it to rock research. The double torsion specimen can be assumed as two elastic torsion bars, of which each cross-section is a rectangle.

For the small deformation, when the width of the torsion bar is much larger than the thickness of the torsion bar, the torsion strain can be calculated by the following equation [21]:

$$
\theta \cong \frac{y}{w_{m}} \cong \frac{6 T a}{w t^{3} G}
$$


where $T$ is the torque $P_{w m} / 2, P$ is the applied load on the torsion bar, $G$ is the shear modulus of the rock, $a$ is the crack length, $t$ is the specimen thickness, $w / 2$ of the torsion bar's width, and $w_{m}$ is the length of twisted arm, and Equation (11) can be rewritten as

$$
\frac{y}{p} \cong \frac{3 w_{m}^{2} a}{w t^{3} G} \cong C,
$$

where $C$ is the elastic compliance of the double torsion specimen. The relation among crack strain energy release rate $g$ and the flexibility of the specimens satisfies the following relationship:

$$
g=\frac{p^{2}}{2}\left[\frac{d C}{d A}\right]=\frac{p^{2}}{2 t_{n}}\left[\frac{d C}{d a}\right],
$$

where $A$ is the area of the crack and $t_{n}$ is the thickness of plane where crack exists. For the double torsion specimen, strain energy release rate can be defined as

$$
g=\frac{3 p^{2} w_{m}^{2}}{2 w t^{3} t_{n} G}
$$

Based on the relations between stress intensity factor $K_{I}$ and the strain energy release rate $g$ and the relationship between elastic modulus $E$ and shear modulus $G$, a lot of research has been done, such as by Cao et al. [22], Andreas et al. [23], Ciccotti et al. [18, 24], and Zhao et al. [25]. The stress intensity factor is introduced in this study.

$$
\mathrm{K}_{I}=P w_{m}\left(\frac{3 E}{2 w d^{3} d_{n} G}\right)^{1 / 2} .
$$

When the load $P$ reaches a critical value of the $P_{C}$ on the specimen, the crack quickly grows, So $K_{I}$ reaches a critical value $K_{I C}$, which is shown as follows:

$$
\mathrm{K}_{I C}=P_{C} w_{m}\left(\frac{3 E}{2 w d^{3} d_{n} G}\right)^{1 / 2}
$$

Tests showed that the compliance change rate can be obtained by the displacement change rate with the given loads or by the load change rate with the given displacement. Under the constant displacement conditions, through the derivative of Equation (12), it can be obtained that

$$
\left[\begin{array}{l}
d a \\
d t
\end{array}\right]=-\frac{w t^{3} E y}{6 w_{m}^{2} p^{2}(1+v)}\left[\frac{d p}{d t}\right] .
$$

Equation (17) shows that if the specimen's size and displacement are known, the subcritical crack growth velocity is related to the load relaxation rate with the given displacement state.
TABLE 3: The specimen mechanical parameters.

\begin{tabular}{lccccc}
\hline$\beta$ & $\begin{array}{c}\text { Number of } \\
\text { sample }\end{array}$ & $\begin{array}{c}\text { Compressive } \\
\text { strength (MPa) }\end{array}$ & $\begin{array}{c}\text { Elastic } \\
\text { modulus } \\
(\mathrm{GPa})\end{array}$ & $\mu_{x z}$ & $\mu_{y z}$ \\
\hline $0^{\circ}$ & 3 & 74.79 & 38.38 & 0.19 & 0.19 \\
$30^{\circ}$ & 3 & 32.21 & 23.00 & 0.20 & 0.21 \\
$45^{\circ}$ & 3 & 24.96 & 21.77 & 0.23 & 0.20 \\
$70^{\circ}$ & 3 & 27.00 & 23.98 & 0.22 & 0.24 \\
$80^{\circ}$ & 3 & 63.39 & 32.96 & 0.30 & 0.18 \\
$90^{\circ}$ & 3 & 70.50 & 41.85 & 0.25 & 0.23 \\
\hline
\end{tabular}

5.2. Stress Intensity Factor and Crack Velocity of the Double Torsion Method. The stress intensity factor was independent of the crack length in this study, and the double torsion test is convenient when it uses opaque materials, such as rocks for which crack length measurements are inconvenient. There are three methods to obtain the crack velocity in the double torsion tests, each of which has a different loading process. The constant load method was used by Li et al. for the original double torsion test [26]. Two other methods are the constant displacement rate and the constant displacement load relaxation method which were introduced by Evans [27]. In the constant displacement load relaxation method, the displacement of the loading point is kept constant during the experiment and the load relaxation is measured with the crack growth. Because the stress intensity factor is the function of the loading and the crack growth rate is the function of the temporal load and decreasing rate of the loading, the relation between the stress intensity factor and the crack growth rate can be obtained over a wide range of loads using a single experimental run. For this reason, the constant displacement load relaxation method was adopted in this paper.

\subsection{Experimental}

5.3.1. Specimen Preparation. Slates of different bedding angles $\left(0^{\circ}, 30^{\circ}, 45^{\circ}, 70^{\circ}, 80^{\circ}\right.$, and $\left.90^{\circ}\right)$ were machined as a rectangle plate double torsion specimen whose standard size was $180 \mathrm{~mm} \times 60 \mathrm{~mm} \times 5 \mathrm{~mm}$ and width-to-thickness ratio was $15: 1 \sim 12: 1$. There was a longitudinal groove on the bottom surface, which was $1 \mathrm{~mm}$ in width and $t / 3$ in depth, and a notch was cut at the end. The crack front proceeded with a straight line starting from a machined initial notch and guided by a side groove thus producing a relaxation of the load. The parallel error between the top surface and the bottom surface of specimens was less than $0.025 \mathrm{~mm}$. The mechanical parameters are listed in Table 3.

5.3.2. Experimental Procedure. The constant displacement load relaxation method only needs to monitor the decrease of the load with time to measure both the stress intensity factor $K_{I}$ and the subcritical crack growth velocity $V$, regardless of the crack length measurement. The double torsion test was processed using an MTS Insight machine in the testing center of the Central South University. Firstly, the slate specimen should be precracked to obtain 


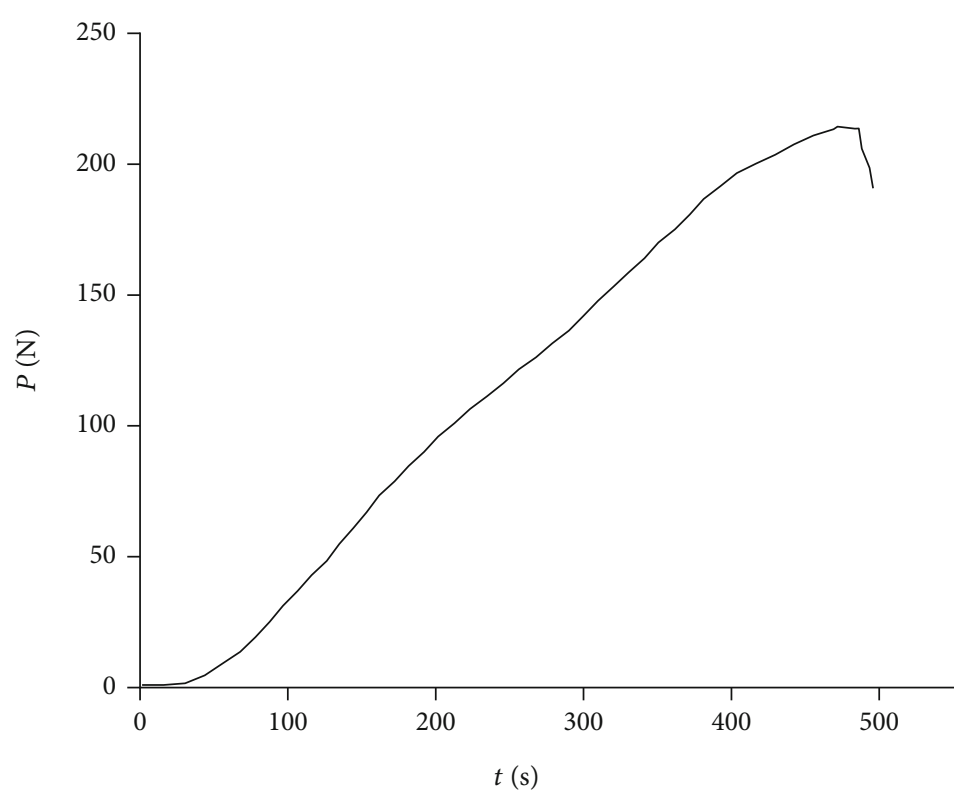

FIGURE 5: Load-time curve of typical specimen in precrack.

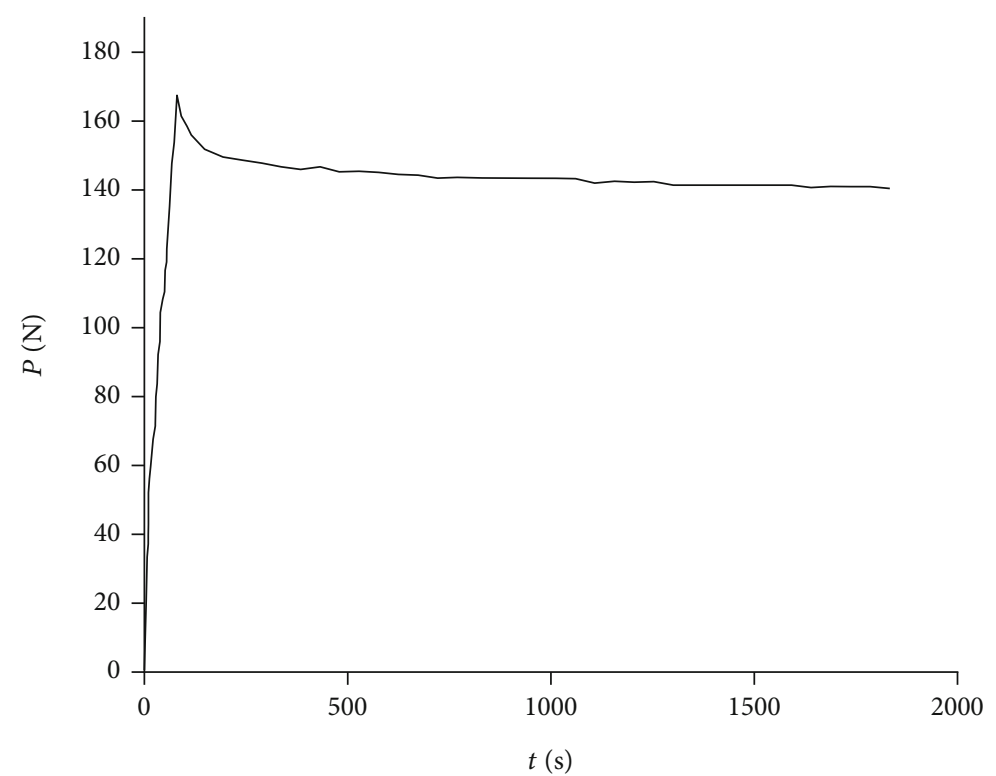

Figure 6: Load-time curve of typical specimen.

reasonable $K_{I C}$ and $K_{I}-V$ data $[28,29]$, and precrack velocity was $0.05 \mathrm{~mm} / \mathrm{min}$. The load-time curve of a typical specimen in precrack is shown in Figure 5. Secondly, the precracked specimen was loaded in $5 \mathrm{~mm} / \mathrm{min}$ displacement velocity during constant displacement load relaxation testing [19]. Then, the displacement of the slate specimen was kept constant when the load comes up to $95 \%$ of the precrack load and the relaxation testing was done $[30,31]$. The load-time data was recorded until the load relaxation was stabilized. The load-time curve and the displacement-time curve of a typical specimen are shown in Figures 6 and 7, respectively.
The precracked specimen was loaded in $20 \mathrm{~mm} / \mathrm{min}$ displacement velocity during the fracture toughness $K_{I C}$ testing, and the critical load $P_{C}$ was recorded. The fracture toughness $K_{I C}$ can be obtained by Equation (17). The loadtime curve of a typical specimen in testing $K_{I C}$ is shown in Figure 5.

\subsubsection{Results and Analysis}

(1)KI-V Relations in Transversely Isotropic Slates. Based on the double torsion testing data, the relation between subcritical crack growth velocity $V$ and the stress intensity factor $K_{I}$ 


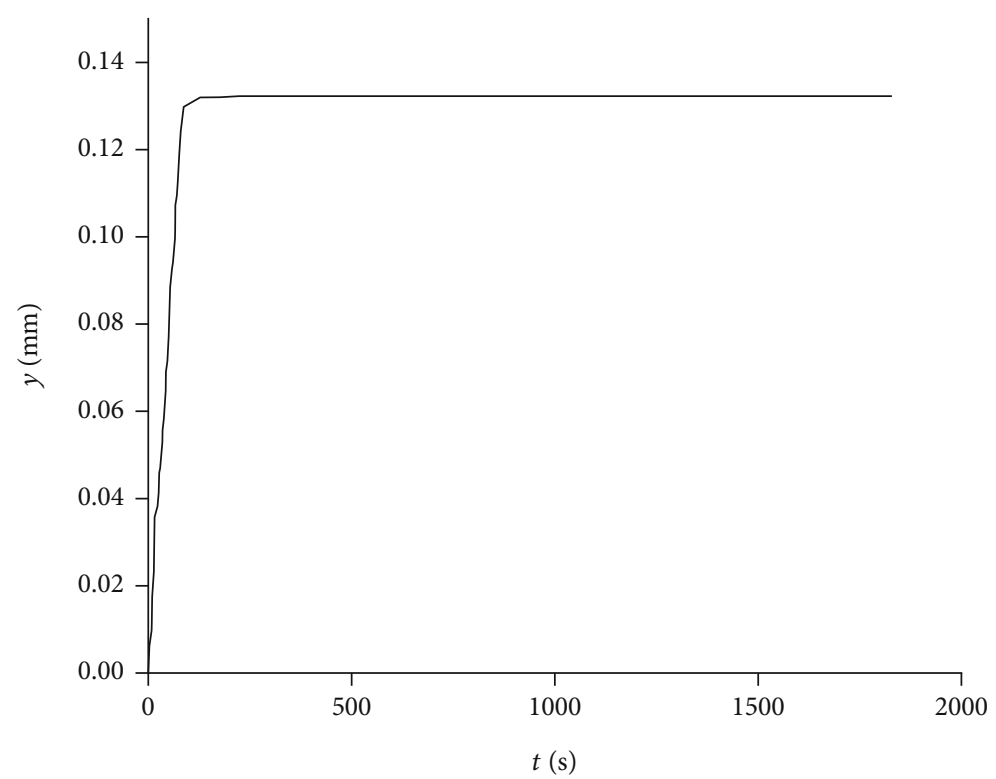

Figure 7: Displacement-time curve of typical specimen.

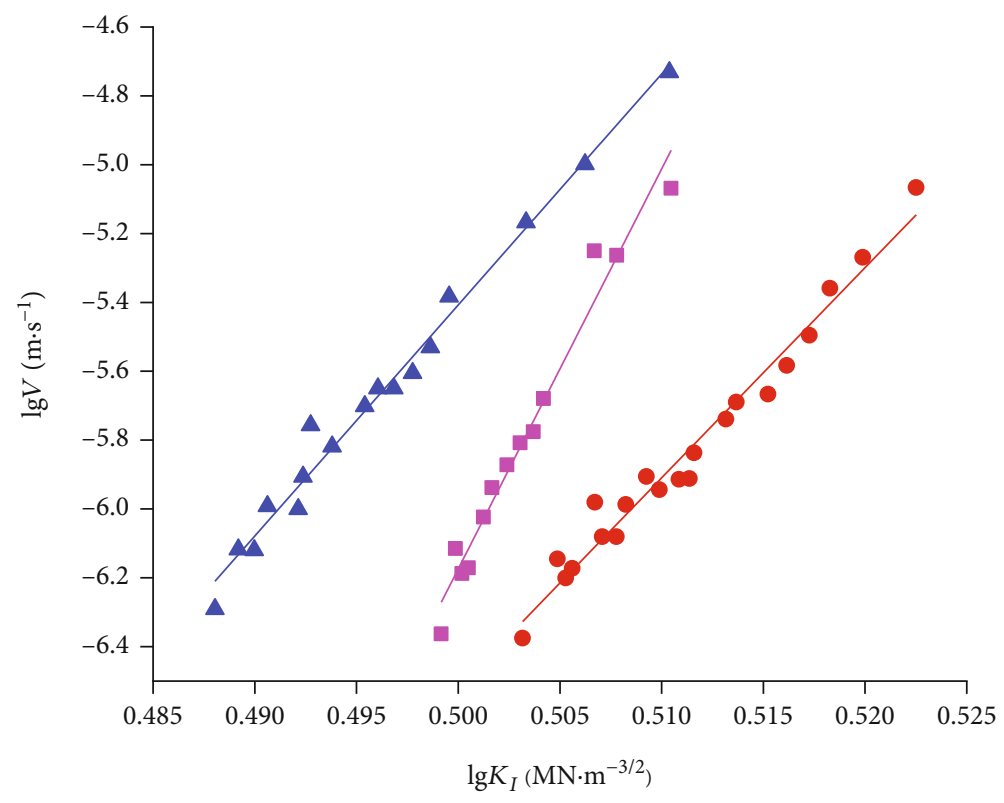
$\Delta 0-1$
- $0-2$
- $0-3$

Figure 8: $\lg K_{I}-\lg V$ curve for the slate specimen of $0^{\circ}$ bedding angles. 


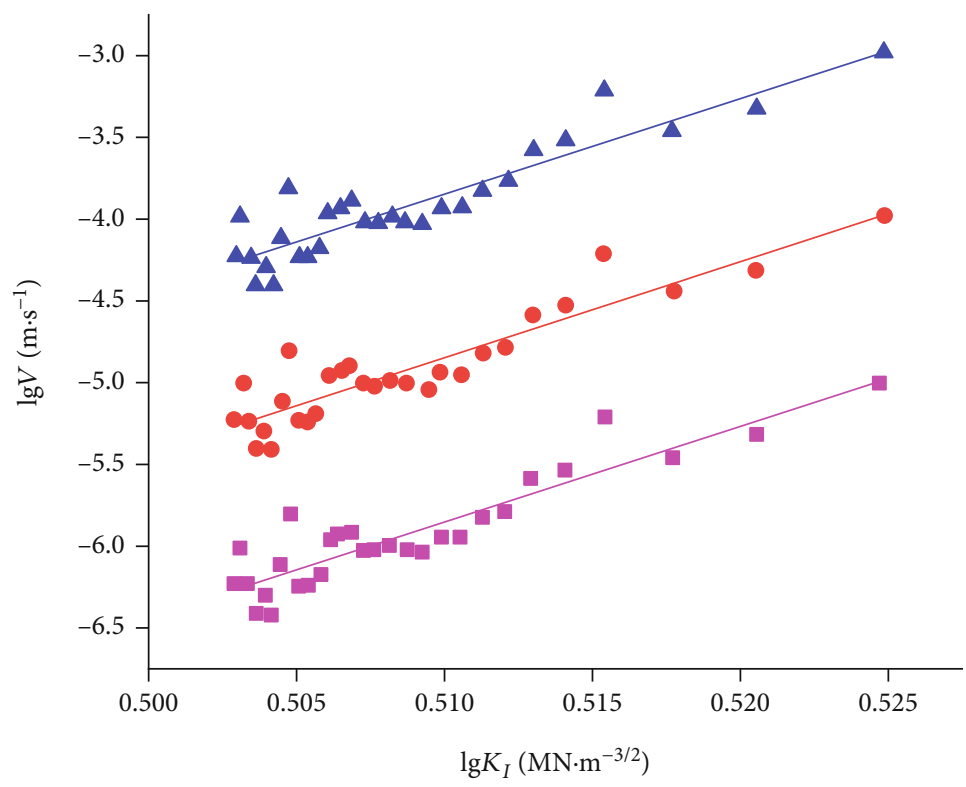
- 1-1
- 1-2
- 1-3

FIgURE 9: $\lg K_{I}-\lg V$ curve for the slate specimen of $30^{\circ}$ bedding angles.

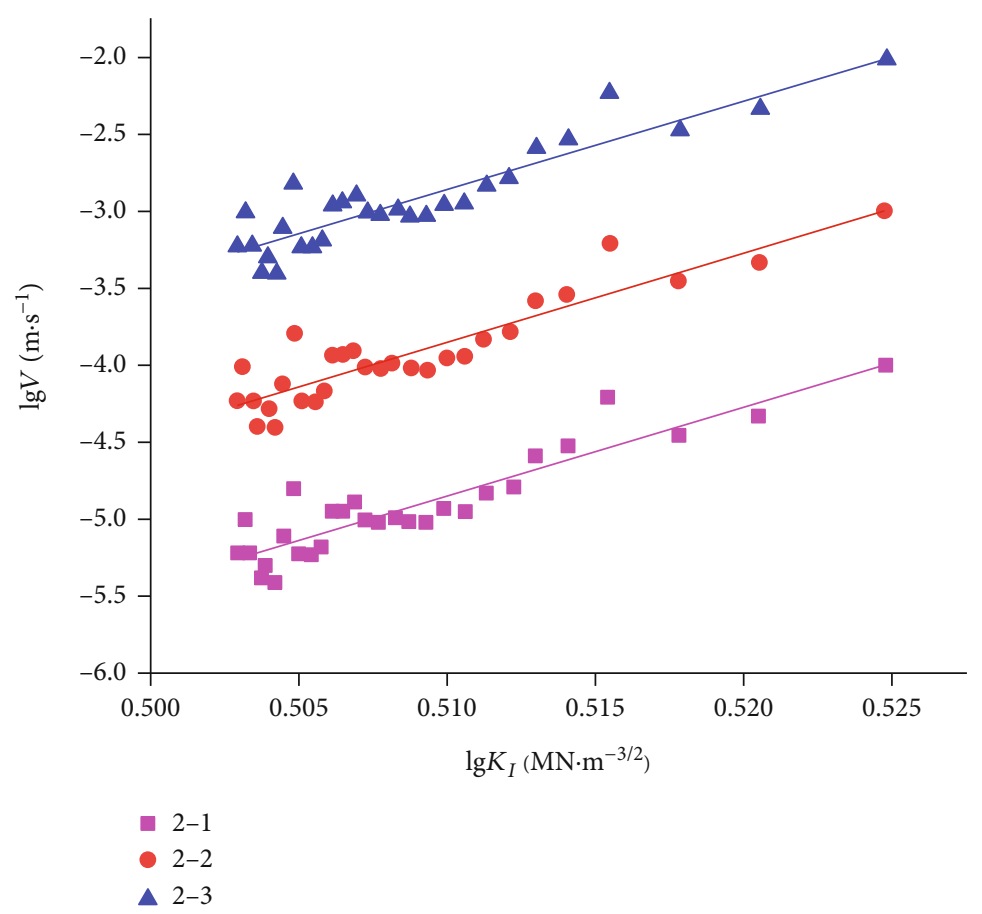

Figure 10: $\lg K_{I}$ - $\lg V$ curve for the slate specimen of $45^{\circ}$ bedding angles.

can be obtained by Equations (15) and (17). According to the Charles theory [32], to analyze the relation between the subcritical crack growth velocity $V$ and the stress intensity factor $K_{I}$, a linear function of double logarithmic space can be used, and their $\lg K_{I}-\lg V$ coordinate points in logarithm coordinates are shown in Figures $8-13 . \lg K_{I}-\lg V$ data are regressed as follows:

$$
\lg V=a+b \lg K_{I}
$$

where $a$ and $b$ are the fitting coefficients. 


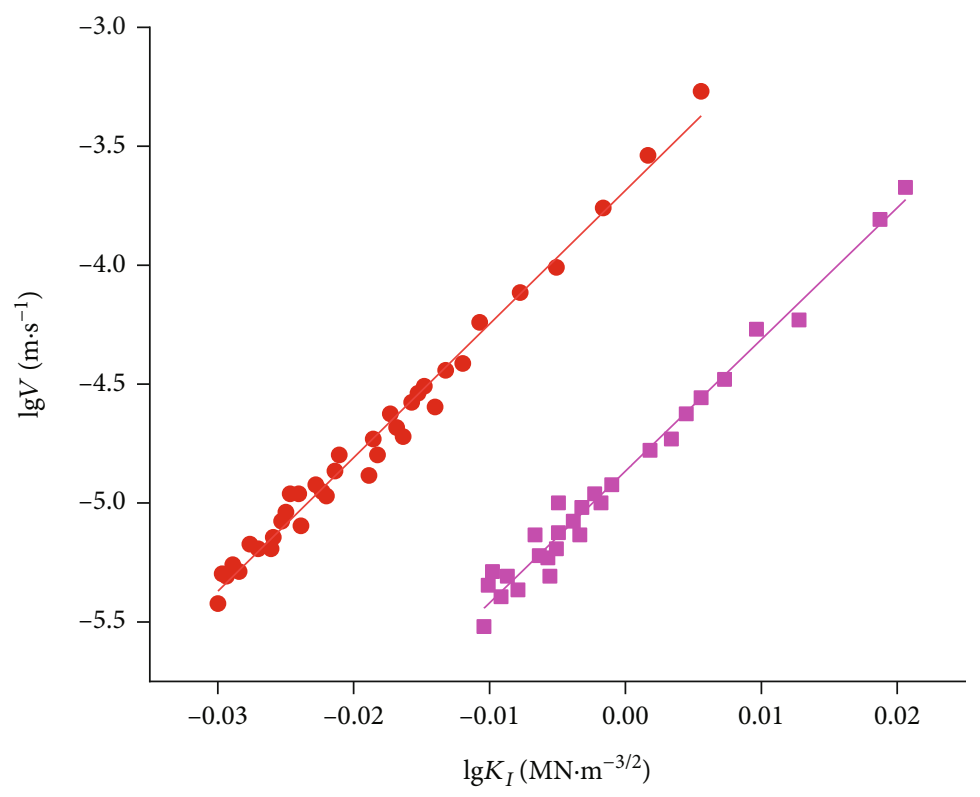

$$
\begin{aligned}
& \text { - } 3-1 \\
& \text { - } 3-3
\end{aligned}
$$

Figure 11: $\lg K_{I}$ - $\lg V$ curve for the slate specimen of $70^{\circ}$ bedding angles.

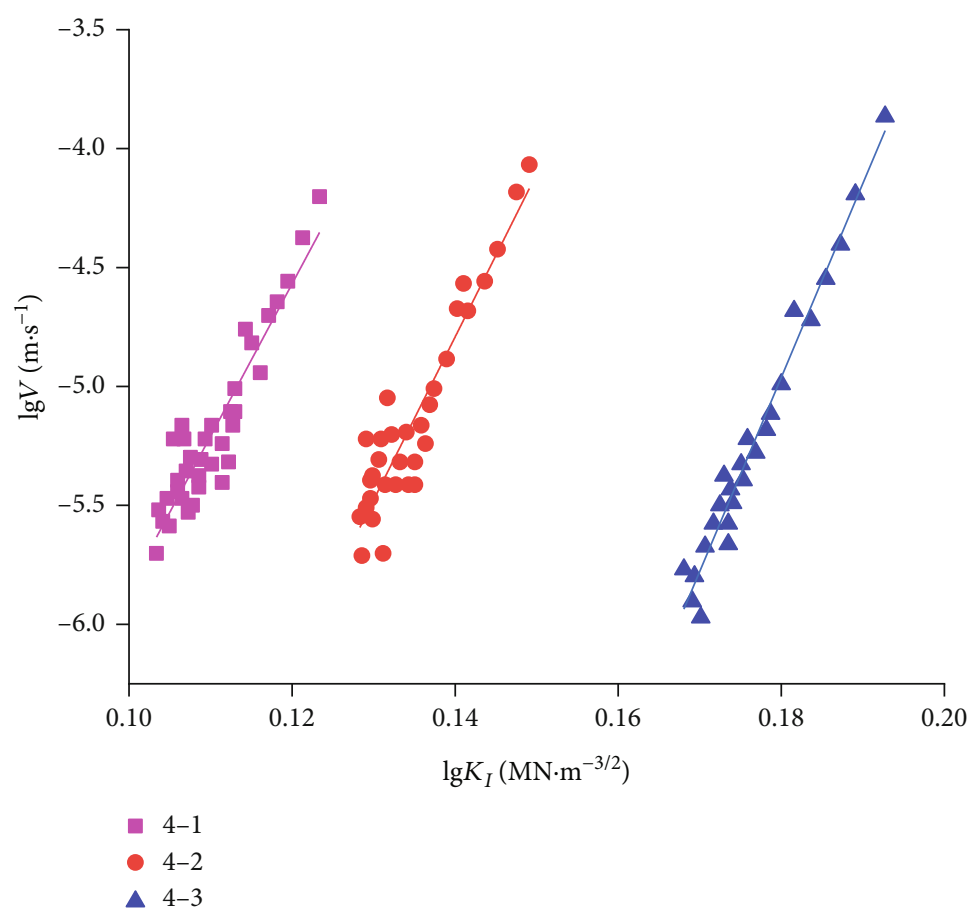

Figure 12: $\lg K_{I}$ - $\lg V$ curve for the slate specimen of $80^{\circ}$ bedding angles.

The power function relation between $V$ and $K_{I}$ is defined as

$$
V=A K_{1}^{n}
$$

where $A$ and $n$ are the fitting coefficients.
Table 4 shows each specimen's subcritical crack growth parameters. Researching rock seepage and stable time effect must be based on the $K_{I C}$ and the relation $K_{I}-V$, from the perspective of fracture mechanics, and these obtained parameters provide basic information for further study of geotechnical engineering seepage and timedependent stability. 


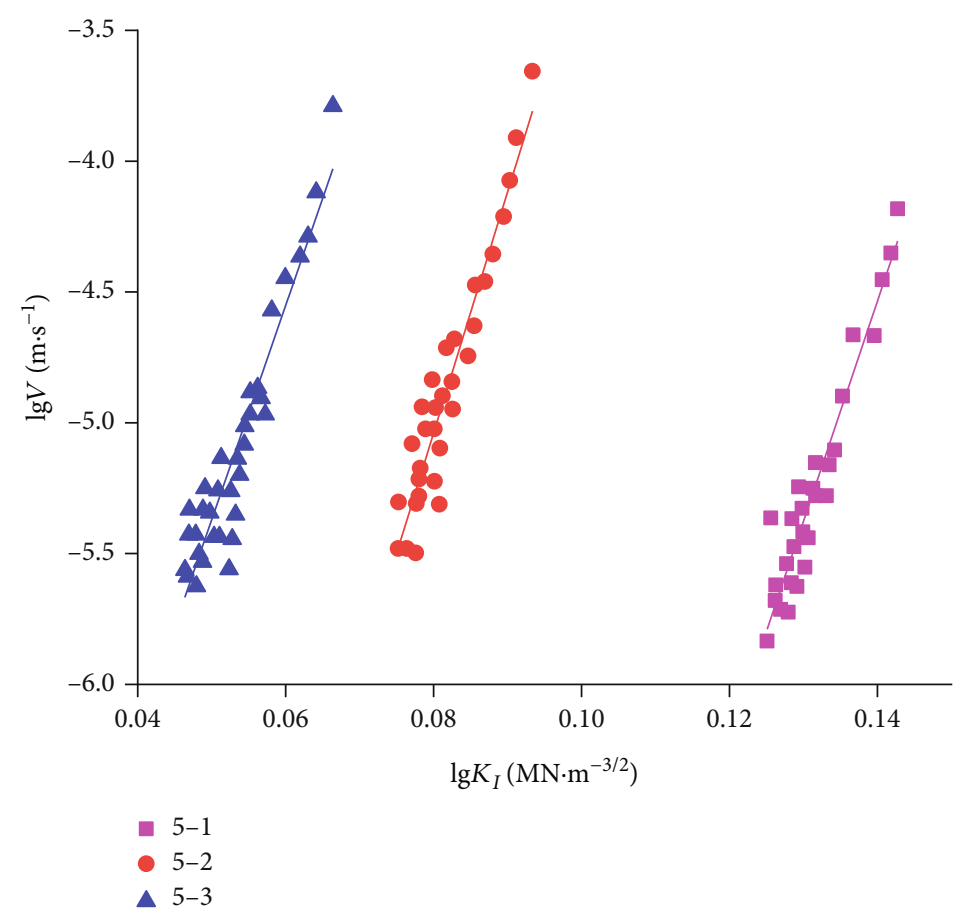

Figure 13: $\lg K_{I}$ - $\lg V$ curve for the slate specimen of $90^{\circ}$ bedding angles.

TABLE 4: The parameters of subcritical crack growth.

\begin{tabular}{cccc}
\hline$\beta$ & Specimen no. & $A$ & $n$ \\
\hline $0^{\circ}$ & $0-1$ & $1.213 \times 10^{-39}$ & 67.010 \\
& $0-2$ & $2.333 \times 10^{-65}$ & 116.891 \\
& $0-3$ & $4.775 \times 10^{-38}$ & 61.588 \\
$30^{\circ}$ & $1-1$ & $2.009 \times 10^{-36}$ & 55.534 \\
& $1-2$ & $1.780 \times 10^{-35}$ & 58.644 \\
& $1-3$ & $1.982 \times 10^{-34}$ & 60.495 \\
$45^{\circ}$ & $2-1$ & $1.984 \times 10^{-35}$ & 59.552 \\
& $2-2$ & $1.992 \times 10^{-34}$ & 61.504 \\
$70^{\circ}$ & $2-3$ & $1.935 \times 10^{-33}$ & 65.532 \\
& $3-1$ & $1.387 \times 10^{-5}$ & 55.743 \\
$80^{\circ}$ & $3-3$ & $2.089 \times 10^{-4}$ & 56.700 \\
& $4-1$ & $1.986 \times 10^{-13}$ & 68.185 \\
& $4-2$ & $1.849 \times 10^{-17}$ & 68.185 \\
& $4-3$ & $4.764 \times 10^{-20}$ & 79.710 \\
$90^{\circ}$ & $5-1$ & $3.972 \times 10^{-17}$ & 84.615 \\
& $5-2$ & $3.656 \times 10^{-13}$ & 92.064 \\
& $5-3$ & $3.622 \times 10^{-10}$ & 81.102 \\
\hline \multirow{3}{*}{} & & &
\end{tabular}

(2)Fracture Toughness (KIC) and the Threshold Values of Different Bedding Angles of Slates. Based on the testing data, the fracture toughness $\left(K_{I C}\right)$ can be obtained by Equation (16), which is shown in Table 5.

Typically, during the testing process of the rock subcritical crack growth rate, with the expansion of the crack, the crack tip's stress intensity factor decreases and the crack extended speed is reduced. When approaching subcritical crack extension threshold value, the crack growth rate is difficult to measure [21]. For rock-like material, the previous researchers did not detect the threshold value, at present. When Wilkins did the research of the subcritical crack expansion of granite, he still did not find the threshold value $\left(K_{0}\right)$ with the expansion speed of $10^{-}$ $12 \mathrm{~m} / \mathrm{s}$ [17]. In this experiment, the lowest subcritical crack extension speed is in the order of $10^{-5}$ to $10^{-6}$. From the point of view of engineering significance, it can be considered that crack growth has been stopped at this time. In this article, the lowest subcritical crack extension velocity is regarded as the stagnation speed of the crack propagation which is shown in Table 6. According to Equation (19), the stress intensity factor $K_{I}$ related to the crack propagation can be obtained as the threshold values $K_{0}$, which are shown in Table 7.

(3)The Relations between the KIC and the Bedding Angles of Slates. The relation between the bedding angles $(\beta)$ and the fracture toughness $\left(K_{I C}\right)$ can be obtained, as shown in Figure 14. It is clear that the basic relation can be expressed as $K_{I C}=0.00043 \beta^{2}-0.05 \beta+4.19, \quad R^{2}=0.97$, 
TABLE 5: Fracture toughness $K_{I C}$ testing value $\left(\mathrm{MN} \cdot \mathrm{m}^{-3 / 2}\right)$.

\begin{tabular}{lccc}
\hline$\beta$ & Specimen no. & $K_{I C}$ & Average $K_{I C}$ \\
\hline \multirow{3}{*}{$0^{\circ}$} & $0-1$ & 4.14 & \\
& $0-2$ & 4.25 & 4.21 \\
$30^{\circ}$ & $0-3$ & 4.24 & \\
& $1-1$ & 3.15 & 3.02 \\
& $1-2$ & 3.00 & \\
$45^{\circ}$ & $1-3$ & 2.91 & \\
& $2-1$ & 2.60 & 2.65 \\
$70^{\circ}$ & $2-2$ & 2.72 & \\
& $2-3$ & 2.63 & 2.79 \\
$80^{\circ}$ & $3-1$ & 2.92 & \\
& $3-3$ & 2.66 & 2.81 \\
& $4-1$ & 2.55 & \\
$90^{\circ}$ & $4-2$ & 3.00 & 2.95 \\
& $4-3$ & 2.88 & \\
\hline
\end{tabular}

TABLE 6: The stagnation speed.

\begin{tabular}{lc}
\hline Parameter & Stagnation speed \\
\hline $0^{\circ}$ & $4.01671 \times 10^{-7}$ \\
$30^{\circ}$ & $5.87673 \times 10^{-7}$ \\
$45^{\circ}$ & $3.93884 \times 10^{-6}$ \\
$70^{\circ}$ & $3.04077 \times 10^{-6}$ \\
$80^{\circ}$ & $1.05808 \times 10^{-6}$ \\
$90^{\circ}$ & $1.36032 \times 10^{-6}$ \\
\hline
\end{tabular}

from which we can see that fracture toughness decreases then increases with the increase of the $\beta$ angle and the relation curves show a "U" type; the result can well reflect the change rule of the $K_{I C}$ with the increase of $\beta$ angles, which is consistent with the theoretical result. Fracture toughness is an important parameter to characterize the rock to resist crack initiation and propagation. This experiment shows that when the bedding angle of the slates is $45^{\circ}$, its fracture toughness is minimal; it means that its capacity to resist crack propagation is minimal, and it is most likely to be damaged during loading.

(4)The Relation between the Threshold Values and the Bedding Angles of Slates. Figure 15 shows the relation between $K_{0}$ and $\beta$ angles for different bedding angles' slates. The basic relationship is $K_{0}=0.00055 \beta^{2}-0.063 \beta+3.369, R^{2}$ $=0.96$. According to Figure 15, it is found that threshold values $\left(K_{0}\right)$ decrease then increase with the increase of the $\beta$ angle. Because of the different bedding angles corresponding to different thresholds, we can know that the threshold values of the slate specimen have obvious anisotropy. When the bedding angle of the slates is $45^{\circ}$, its
TABLe 7: Threshold values $K_{0}$.

\begin{tabular}{|c|c|c|c|}
\hline$\beta$ & Specimen no. & $K_{0}$ & $\frac{K_{0}}{K_{I C}}$ \\
\hline \multirow{3}{*}{$0^{\circ}$} & $0-1$ & 3.268 & 0.789 \\
\hline & $0-2$ & 3.331 & 0.784 \\
\hline & $0-3$ & 3.239 & 0.764 \\
\hline \multirow[t]{2}{*}{ Average } & & 3.279 & 0.779 \\
\hline & $1-1$ & 2.218 & 0.704 \\
\hline \multirow[t]{2}{*}{$30^{\circ}$} & $1-2$ & 2.218 & 0.739 \\
\hline & $1-3$ & 2.621 & 0.901 \\
\hline \multirow[t]{2}{*}{ Average } & & 2.352 & 0.781 \\
\hline & $2-1$ & 1.348 & 0.518 \\
\hline \multirow[t]{2}{*}{$45^{\circ}$} & $2-2$ & 1.440 & 0.529 \\
\hline & $2-3$ & 1.345 & 0.511 \\
\hline \multicolumn{2}{|l|}{ Average } & 1.378 & 0.520 \\
\hline \multirow{2}{*}{$70^{\circ}$} & $3-1$ & 1.548 & 0.530 \\
\hline & $3-3$ & 1.713 & 0.618 \\
\hline \multirow[t]{2}{*}{ Average } & & 1.631 & 0.574 \\
\hline & $4-1$ & 1.838 & 0.686 \\
\hline \multirow[t]{2}{*}{$80^{\circ}$} & $4-2$ & 1.638 & 0.642 \\
\hline & $4-3$ & 2.016 & 0.672 \\
\hline \multirow[t]{2}{*}{ Average } & & 1.838 & 0.661 \\
\hline & $5-1$ & 2.391 & 0.759 \\
\hline \multirow[t]{2}{*}{$90^{\circ}$} & $5-2$ & 2.240 & 0.772 \\
\hline & $5-3$ & 2.166 & 0.774 \\
\hline Average & & 2.266 & 0.768 \\
\hline
\end{tabular}

threshold value is minimal; it means that when the slate specimen is under load, crack initiation and expansion are most likely to happen, which can cause slate specimen failure.

\section{Conclusion}

Transversely isotropic elastic parameters and the subcritical crack growth of different bedding angle slate specimens were studied, and a series of uniaxial compression tests and the double torsion constant displacement load relaxation methods were carried out. The following conclusions can be drawn based on this study:

(1) Based on the slate specimen elastic parameters obtained from the uniaxial compression test and the double torsion test, it is clear that the slate is significantly transversely isotropic

(2) The relations of the mode-I stress intensity factor $K_{I}$ versus the subcritical crack growth velocity $V$ and the fracture toughness $K_{I C}$ were obtained by the double torsion constant displacement load relaxation method; the threshold values were calculated. The calculation results indicate that $\mathrm{lg}$ $K_{I}-\lg V$ relations of different bedding angle slate 


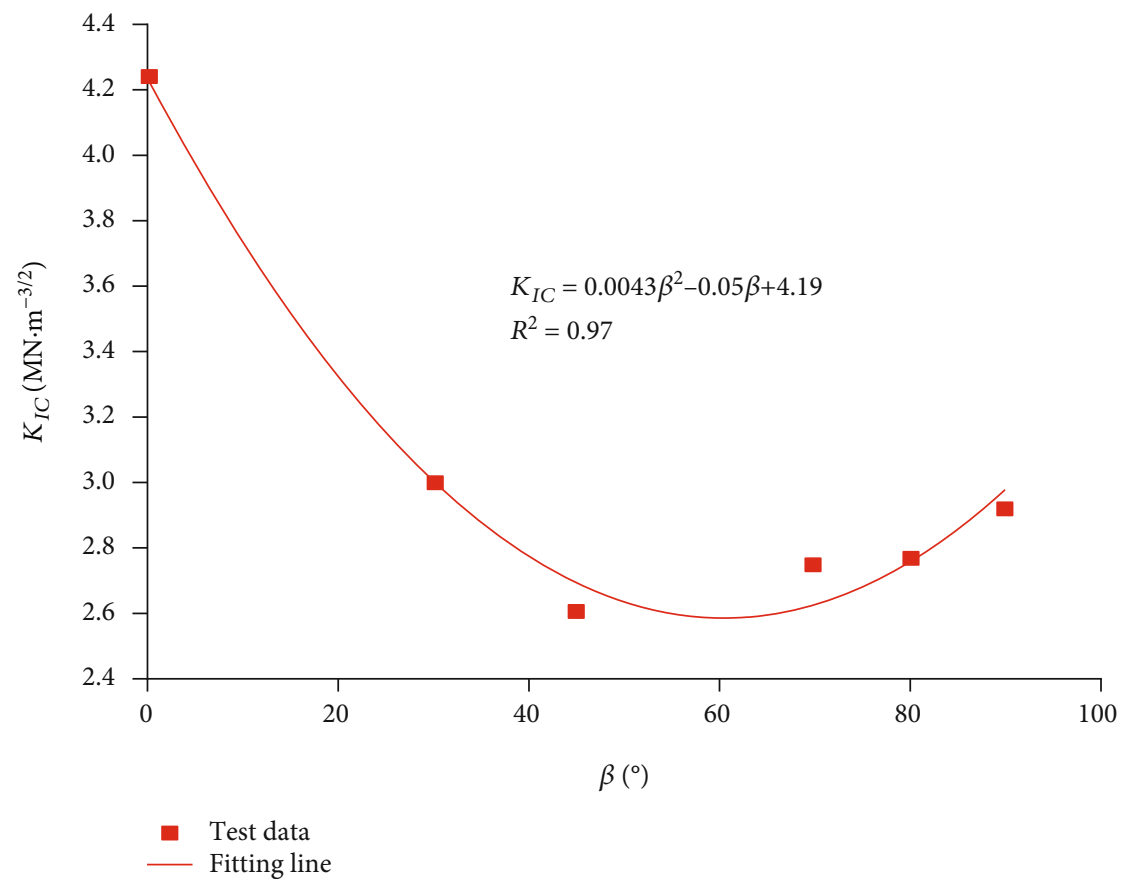

FIgURE 14: Relation between fracture toughness and $\beta$ angle.

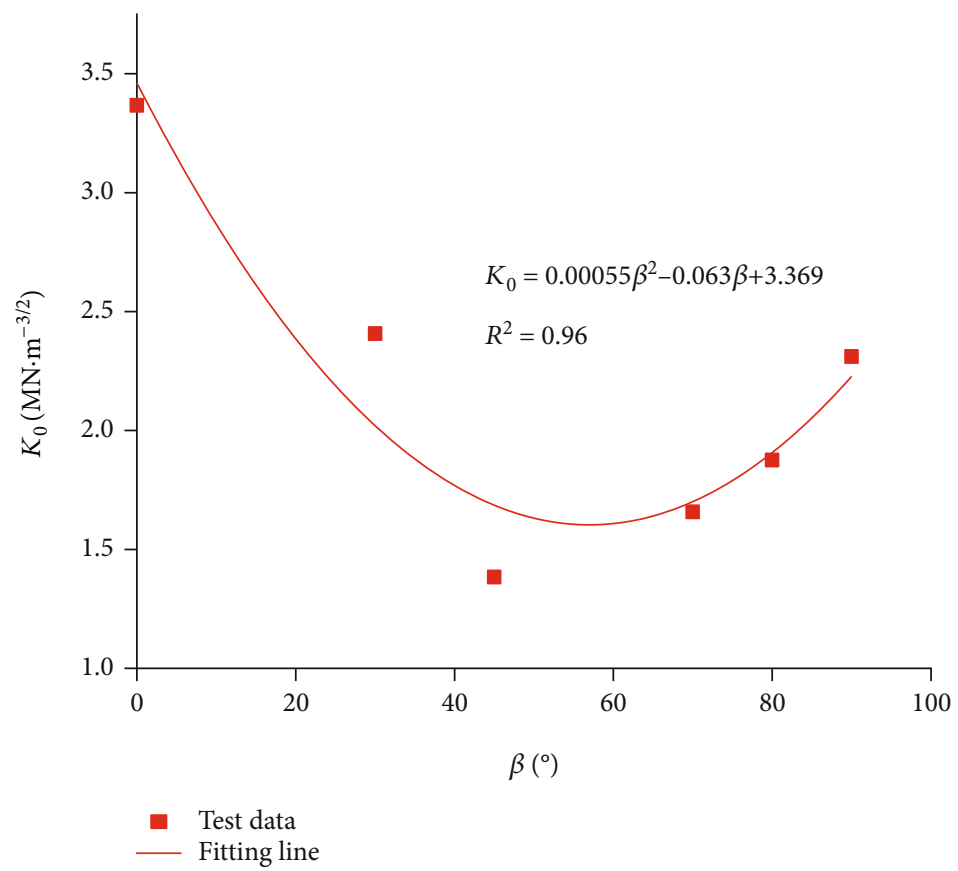

FIGURE 15: Relation between threshold values and $\beta$ angle. 
specimens measured are in accordance with the linear rule, and they are in great agreement with the Charles theory

(3) The threshold value $K_{0}$ of subcritical crack propagation was obtained from the perspective of engineering applications. In this experiment, the range of $K_{0} / K_{I C}$ for these different bedding angle slates is from 0.511 to 0.789 , and the lowest subcritical crack extension speed of the different bedding angle slates is in the order of $10^{-5}$ to $10^{-6}$

(4) The slate's bedding angle has an inevitable impact on its mechanical properties. The uniaxial compression, fracture toughness, and threshold values decrease then increases with the increase of the $\beta$ angle and the relation curve is U-shaped. It is also observed that when the $\beta$ angle of the slate is $45^{\circ}$, its fracture toughness is minimal. Therefore, crack initiation and crack propagation are generated under loading, resulting in the failure of the slate

\section{Data Availability}

The data used to support the findings of this study are included within the article.

\section{Conflicts of Interest}

The authors declare that they have no known competing financial interests or personal relationships that could have appeared to influence the work reported in this paper.

\section{Acknowledgments}

This paper receives funding from a project (No. 51979293) supported by the National Natural Science Foundation of China. The authors wish to acknowledge this support.

\section{References}

[1] S. Wang, J. Li, and C. Wang, "Experimental study on subcritical crack propagation in transverse isotropic rocks," Journal of Central South University(Science and Technology), vol. 48, no. 6, pp. 1607-1614, 2017.

[2] M. Hakala, H. Kuula, and J. A. Hudson, "Estimating the transversely isotropic elastic intact rock properties for in situ stress measurement data reduction: a case study of the Olkiluoto mica gneiss, Finland," International Journal of Rock Mechanics and Mining Sciences, vol. 44, no. 1, pp. 14-46, 2007.

[3] S. Xie, H. Lin, Y. Chen, R. Yong, W. Xiong, and S. Du, "A damage constitutive model for shear behavior of joints based on determination of the yield point," International Journal of Rock Mechanics and Mining Sciences, vol. 128, p. 104269, 2020.

[4] S.-Q. Yang, P.-F. Yin, B. Li, and D.-S. Yang, "Behavior of transversely isotropic shale observed in triaxial tests and Brazilian disc tests," International Journal of Rock Mechanics and Mining Sciences, vol. 133, p. 104435, 2020.

[5] P. Lade, "Modeling failure in cross-anisotropic frictional materials," International Journal of Solids and Structures, vol. 44, no. 16, pp. 5146-5162, 2007.
[6] H. Lin, S. Xie, R. Yong, Y. Chen, and S. Du, "An empirical statistical constitutive relationship for rock joint shearing considering scale effect," Comptes Rendus Mécanique, vol. 347, no. 8, pp. 561-575, 2019.

[7] X. Zhou, J. Li, and H. Lin, "Analysis of internal stress distribution and mechanics characteristics of pre-existing cavity in brittle rock under triaxial cyclic loading," Frontiers in Earth Science, vol. 8, 2020.

[8] X.-P. Zhou, J.-Z. Zhang, and L. N. Y. Wong, "Experimental study on the growth, coalescence and wrapping behaviors of 3D cross-embedded flaws under uniaxial compression," Rock Mechanics and Rock Engineering, vol. 51, no. 5, pp. 13791400, 2018.

[9] R. Cao, R. Yao, J. Meng, Q. Lin, H. Lin, and S. Li, "Failure mechanism of non-persistent jointed rock-like specimens under uniaxial loading: laboratory testing," International Journal of Rock Mechanics and Mining Sciences, vol. 132, p. 104341, 2020.

[10] F. Zhang, X. Wang, and J. Lu, "translators," in Fracture mechanics, China Architecture \& Building Press, Beijing, 1981.

[11] X. Zhou, H. Cheng, and Y. Feng, "An experimental study of crack coalescence behaviour in rock-like materials containing multiple flaws under uniaxial compression," Rock Mechanics and Rock Engineering, vol. 47, no. 6, pp. 1961-1986, 2013.

[12] G. Liu and M. Cai, "Modeling time-dependent deformation behavior of brittle rock using grain-based stress corrosion method," Computers and Geotechnics, vol. 118, p. 103323, 2020.

[13] R. Gholami and V. Rasouli, "Mechanical and elastic properties of transversely isotropic slate," Rock Mechanics and Rock Engineering, vol. 47, no. 5, pp. 1763-1773, 2014.

[14] Z. Wang, Z. Zong, L. Qiao, and W. Li, "Elastoplastic model for transversely isotropic rocks," International Journal of Geomechanics, vol. 18, no. 2, p. 04017149, 2018.

[15] B. Amadei, "Importance of anisotropy when estimating and measuring in situ stresses in rock," International Journal of Rock Mechanics and Mining Sciences \& Geomechanics Abstracts, vol. 33, no. 3, pp. 293-325, 1996.

[16] L. Milou, Rock Mechanics, China Coal Industry Publishing House, Beijing, 1981.

[17] D. Williams and A. Evans, "A simple method for studying slow crack growth," Journal of Testing and Evaluation, vol. 1, no. 2, pp. 264-270, 1973.

[18] M. Ciccotti, N. Negri, G. Gonzato, and F. Mulargia, "Practical application of an improved methodology for the double torsion load relaxation method," International Journal of Rock Mechanics and Mining Sciences, vol. 38, no. 4, pp. 569-576, 2001.

[19] M. Saadaoui, P. Reynaud, G. Fantozzi, F. Peronnet, and J. P. Caspar, "Slow crack growth study of plaster using the double torsion method," Ceramics International, vol. 26, no. 4, pp. 435-439, 2000.

[20] Y. Nara and K. Kaneko, "Study of subcritical crack growth in andesite using the double torsion test," International Journal of Rock Mechanics and Mining Sciences, vol. 42, no. 4, pp. 521-530, 2005.

[21] H. Xiao, "Rheologic damage study of three gorges ship lock high slope and analysis on in-situ measured deformation," Chinese Journal of Rock Mechanics and Engineering, vol. 18, no. 5, pp. 497-502, 1999.

[22] P. CAO, L. I. Jiang-teng, and H.-p. YUAN, “Testing study of subcritical crack growth rate and fracture toughness in 
different rocks," Transactions of Nonferrous Metals Society of China, vol. 16, no. 3, pp. 709-713, 2006.

[23] K. Andreas, P. Eckhard, W. Jorg, and B. Wolfgang, "Subcritical crack growth in $\mathrm{AI}_{2} \mathrm{O}_{3}$ with submicron grain size," Journal of the European Ceramic Society, vol. 23, no. 1, pp. 81-89, 2003.

[24] M. Ciccotti, G. Gonzato, and F. Mulargia, "The double torsion loading configuration for fracture propagation: an improved methodology for the load-relaxation at constant displacement," International Journal of Rock Mechanics and Mining Sciences, vol. 37, no. 7, pp. 1103-1113, 2000.

[25] Y. Zhao, L. Zhang, J. Liao, W. Wang, Q. Liu, and L. Tang, "Experimental study of fracture toughness and subcritical crack growth of three rocks under different environments," International Journal of Geomechanics, vol. 20, no. 8, p. 04020128, 2020.

[26] K. Li, Y. Cheng, Z. Y. Yin, D. Han, and J. Meng, "Size effects in a transversely isotropic rock under Brazilian tests: laboratory testing," Rock Mechanics and Rock Engineering, vol. 53, no. 6, pp. 2623-2642, 2020.

[27] A. Evans, "A method for evaluating the time dependent failure characteristics of brittle materials and its applications to polycrystalline alumina," Journal of Materials Science, vol. 7, no. 11, pp. 37-46, 1972.

[28] B. Atiunson, "Fracture toughness of Tennessee sandstone and Carrara marble using the double torsion testing method," International Journal of Rock Mechanics and Mining Sciences \& Geomechanics Abstracts, vol. 16, no. 1, pp. 49-53, 1979.

[29] X.-P. Zhou, Y.-T. Wang, J.-Z. Zhang, and F.-N. Liu, "Fracturing behavior study of three-flawed specimens by uniaxial compression and 3D digital image correlation: sensitivity to brittleness," Rock Mechanics and Rock Engineering, vol. 52, no. 3, pp. 691-718, 2019.

[30] M. Ciccotti, N. Negri, L. Sassi, G. Gonzato, and F. Mulargia, "Elastic and fracture parameters of Etna, Stromboli, and Vulcano lava rocks," Journal of Volcanology and Geothermal Research, vol. 98, no. 1-4, pp. 209-217, 2000.

[31] M. E. Ebrahimi, J. Chevalier, and G. Fantozzi, "Slow crackgrowth behavior of alumina ceramics," Journal of Materials Research, vol. 15, no. 1, pp. 142-147, 2000.

[32] E. Z. Lajtai and L. P. Bielus, "Stress corrosion cracking of Lac du Bonnet granite in tension and compression," Rock Mechanics and Rock Engineering, vol. 19, no. 2, pp. 71-87, 1986. 